University of Nebraska - Lincoln

DigitalCommons@University of Nebraska - Lincoln

\title{
Behavioral Response of Stomoxys calcitrans (Diptera: Muscidae) to Conspecific Feces and Feces Extracts
}

\author{
David Carlson \\ USDA-ARS
}

Raul Alzogaray

Centro de Investigaciones de Plagas e Insecticidas

Jerome Hogsette

USDA-ARS

Follow this and additional works at: https://digitalcommons.unl.edu/usdaarsfacpub

Part of the Agricultural Science Commons

Carlson, David; Alzogaray, Raul; and Hogsette, Jerome, "Behavioral Response of Stomoxys calcitrans (Diptera: Muscidae) to Conspecific Feces and Feces Extracts" (2000). Publications from USDA-ARS / UNL Faculty. 1017.

https://digitalcommons.unl.edu/usdaarsfacpub/1017

This Article is brought to you for free and open access by the U.S. Department of Agriculture: Agricultural Research Service, Lincoln, Nebraska at DigitalCommons@University of Nebraska - Lincoln. It has been accepted for inclusion in Publications from USDA-ARS / UNL Faculty by an authorized administrator of DigitalCommons@University of Nebraska - Lincoln. 


\title{
Behavioral Response of Stomoxys calcitrans (Diptera: Muscidae) to Conspecific Feces and Feces Extracts
}

\author{
DAVID A. CARLSON, ${ }^{1}$ RAUL A. ALZOGARAY, ${ }^{2}$ aNd JEROME A. HOGSETTE ${ }^{1}$
}

\begin{abstract}
J. Med. Entomol. 37(6): 957-961 (2000)
ABSTRACT The attraction response of Stomoxys calcitrans (L.) to its own feces was evaluated in a triple cage olfactometer. Both time- and concentration-response relationships were obtained for female $S$. calcitrans exposed to cellulose sponges impregnated with fresh fly feces or filter papers treated with chloroform:methanol extracts of fresh fly feces in 6-min tests. Attraction to feces collected on cellulose sponges decreased as the air flow increased. Feces collected on cellulose sponges and held for 28-31 d retained attractive activity. More female flies were attracted than males to feces on sponges or to polar solvent extracts of feces-contaminated cages. The activity of feces extract on filter paper decreased rapidly. Chemical identification of the active compounds present could lead to useful baits for traps.
\end{abstract}

KEY WORDS Stomoxys calcitrans, stable fly, triple cage olfactometer, feces, attraction

The STABle FLy, Stomoxys calcitrans (L.), is a cosmopolitan insect that usually lives in close association with large mammals. Both sexes are hemotophagous, and their feeding activity can cause weight loss in livestock (Wieman et al. 1992). Although humans are not the primary source of blood for S. calcitrans, severe and prolonged outbreaks occur in late summer and fall along the West Florida Gulf Coast and the Great Lakes region (Foil and Hogsette 1994). These flies interfere significantly with tourism and make outdoor activities intolerable (Newson 1977). Large numbers of flies also have been reported along Atlantic coast beaches and at inland locations in the United States (Jones et al. 1998). For addition of chemical baits to traps, Hammack and Hesler (1996) reported the attraction of $S$. calcitrans to several synthetic phenylpropanoids and sticky traps in the United States. Mihok et al. (1995) reported the attraction of African Stomoxines of 11 taxa to Vavuoa traps using the attractant 1-octen-3-ol, although S. calcitrans was at low abundance. Holloway and Phelps (1991) reported the attraction of African Stomoxines to F3 traps with the aid of 1-octen-3-ol. However, this chemical has not been effective to date in test traps in Florida against S. calcitrans (D.A.C., unpublished data). Mullens et al. (1995) was unsuccessful in increasing trap catches in California with 1-octen-3-ol. Cilek et al. (1999) used sticky Alsynite panels combined with chemical attractants for S. calcitrans in north Florida, and found that the usual increase with $\mathrm{CO}_{2}$ increased catch up to sixfold with a

\footnotetext{
${ }^{1}$ Center for Medical, Agricultural and Veterinary Entomology (CMAVE), USDA-ARS, 1600/1700 SW 23rd Drive, Gainesville, FL 32608.

${ }^{2}$ Centro de Investigaciones de Plagas e Insecticidas (CIPEIN/ CITEFA-CONICET), Zufriategui 4380, (1603) Villa Martelli, Prov. Buenos Aires, Argentina.
}

mixture of three phenols, but little increase (only 4\%) with 1-octen-3-ol.

Attraction responses of insects to feces from individuals of the same species have been reported in several taxa including reduviid bugs (Schofield and Patterson 1977, Ondarza et al. 1986, Lorenzo Figueras et al. 1994), body lice (Wigglesworth 1941, Mumcuoglu et al. 1986), cockroaches (Metzger 1995), and boll weevils (Mitchell et al. 1975). Efforts with house fly extracts including fecal lipid extracts (Gouck and Schreck 1965, Mayer and James 1971, Mayer et al. 1972) resulted in the identification of a female-produced sex pheromone present in feces (Carlson et al. 1971).

Attempts to demonstrate a female-produced sex pheromone in S. calcitrans did not result in the isolation of a volatile sex pheromone (Muhammed et al. 1975), but later work demonstrated that a major maleproduced alkatriene, 1,7,13-pentacosatriene, was present (Carlson and Mackley 1985). Additional research showed enhanced mating strike activity by males to several nonvolatile methyl-branched hydrocarbons produced by females (Uebel et al. 1975). No work with fly feces was reported in these studies. Recent studies with $S$. calcitrans in a triple cage olfactometer showed good responses to human skin odors, but not to synthetic candidate mosquito attractants (Alzogaray and Carlson 2000) or to odors from fresh flowers of goldenrod (Solidago spp., D.A.C., unpub.).

Our studies continue to improve attraction to traps for monitoring or removal fly control. The objective of the current work was to evaluate the behavioral response of adult $S$. calcitrans to conspecific feces and feces extracts using a triple cage olfactometer. 


\section{Materials and Methods}

Adult S. calcitrans were unfed and 24-36 h old when tested, except when otherwise stated. Flies were obtained from the USDA colonies (Hogsette 1992) and reared on bovine blood as described previously. Tests consisted of four to eight replicates with 30-40 freshly introduced flies in each cage, as described in the figure captions in Alzogaray and Carlson (2000).

All experiments were performed in a triple cage olfactometer with three cages (Posey et al. 1998) supported on a single base, with dual removable traps and sleeve assemblies for each cage. There was an opening in the rear of each test cage covered with a $0.7-\mathrm{mm}$ mesh window screen in a frame. This rear opening allowed acclimation of flies to conditioned air for 1-3 $\mathrm{h}$ before tests were conducted at 0900, 1100, and 1300 hours. Air flow through the dual traps into dual ports into each test cage was controlled by a single sliding door with two holes. The air speeds were adjusted to one of the following three; $0.10-0.15,0.25-0.30$, or $0.45-0.50 \mathrm{~m} \mathrm{~s}^{-1}$. Both traps captured flies that passed from the test cage upstream through a screen cone during 6-min tests. Attraction was expressed as (flies trapped by attractant - flies trapped in the unbaited trap) $\times 100 /$ total number of flies in the cage. Flies rarely were captured in the control ports.

For measuring the response to fly feces, rectangular pieces of cellulose sponge ( 11.4 by 3.8 by $0.8 \mathrm{~cm}$ ) were suspended from $5 \mathrm{~cm}$ wires in standard colony cages ( 40 by 40 by $45 \mathrm{~cm}$ ) for $1-7 \mathrm{~d}$ for flies to rest and defecate upon. Fly density inside each cage was $\approx 5,000$ individuals, and blood was available ad libitum. Sponges were removed from the cages just before use. Sponges used in aging experiments were held $3 \mathrm{~d}$ inside the colony cages, then placed in plastic bags with an open end for aging up to $31 \mathrm{~d}$ to allow air contact before testing. Water-washed, but unexposed sponges were used as controls. For bioassays, sponges were stood on edge in the upwind end of the trap on a small metal platform so that the long sides would be parallel to the passing airflow. Treated filter paper was placed similarly to ensure airflow directly into the trap.

Feces extract was obtained by washing the sponges with a mixture of chloroform:methanol (2:1). Sponges (five), which were held $3 \mathrm{~d}$ in the colony cages, were submerged in $60 \mathrm{ml}$ of extraction solvent in a beaker, removed, compressed, then shaken manually for $10 \mathrm{~s}$. Aliquots of extract $(2 \mathrm{ml}$ of $40 \mathrm{ml}$ ) were pipetted onto filter paper $(11 \mathrm{~cm}$ diameter, Whatman \#1, Hillsboro, OR) $1 \mathrm{~h}$ before the experiments began except when otherwise stated.

Extracts were obtained from rearing cages after $14 \mathrm{~d}$ of fly habitation by rinsing the lower inner surfaces of the cages with solvent (chloroform/methanol, 2:1; methylene chloride; hexane; $2 \times 100 \mathrm{ml}$ ) that was collected and concentrated to $20 \mathrm{ml}$ using a rotary evaporator. Water $(40 \mathrm{ml})$ also was used. The concentrates were used as obtained. Aliquots of the hexane and chloroform/methanol extracts were added to a column $(2$ by $50 \mathrm{~cm})$ of hexane-slurried silica gel

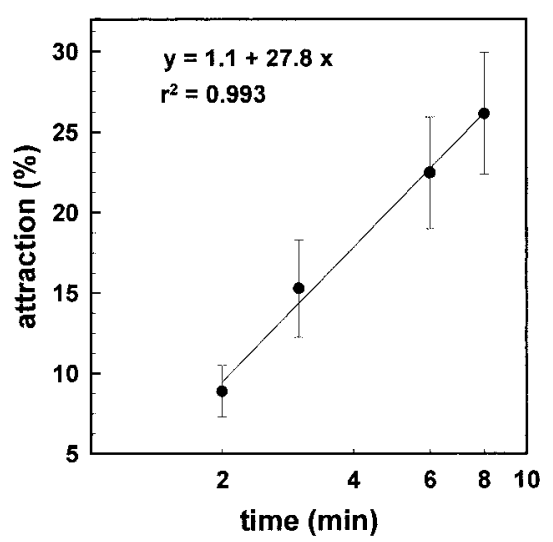

Fig. 1. Time-attraction relationship of female S. calcitrans to conspecific feces. Each value is the mean of nine replicates $(n=29-35$ flies $)$. Vertical bars indicate \pm SE.

(60-200 mesh, Aldrich, Milwaukee, WI), and eluted in 200-ml fractions of hexane, hexane-ether (5\%), hexane-ether (15\%), and chloroform-methanol (2:1). These fractions were concentrated to $20 \mathrm{ml}$ for bioassays. Water $(40 \mathrm{ml})$ also was used as a solvent and used as collected.

Results were analyzed using general linear models procedure of the SAS System (SAS Institute 1989).

\section{Results}

Feces on Sponges. The attraction of female S. calcitrans to feces on cellulose sponges (which were held $3 \mathrm{~d}$ in colony cages) increased linearly as a function of the log of exposure time (Fig. 1). When the air speed into the olfactometer was varied, significant differences in attraction were dependent on air flow $(F=$ 4.7 ;f $=2,18 ; P=0.02$ ) (Fig. 2), with the highest attraction observed at $0.10-0.15 \mathrm{~m} \mathrm{~s}^{-1}$ air speed in the standard 6-min tests. The quantity of feces on the

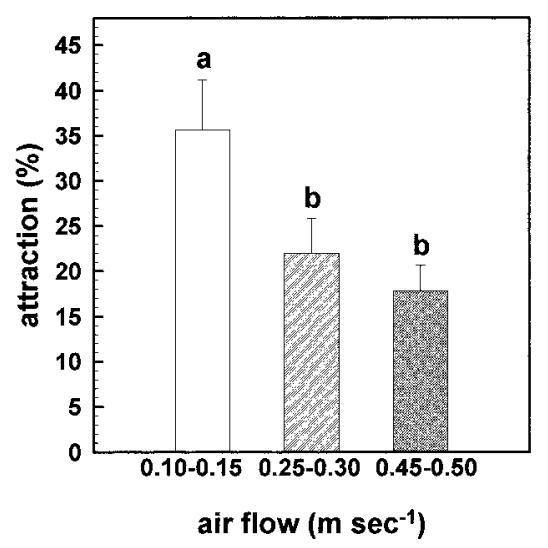

Fig. 2. Attraction of female S. calcitrans to conspecific feces at three air flows. Different letters indicate significant differences due to air flow $(P<0.05)$. Each value is the mean of seven replicates $(n=34-35)$. Vertical bars indicate \pm SE. 


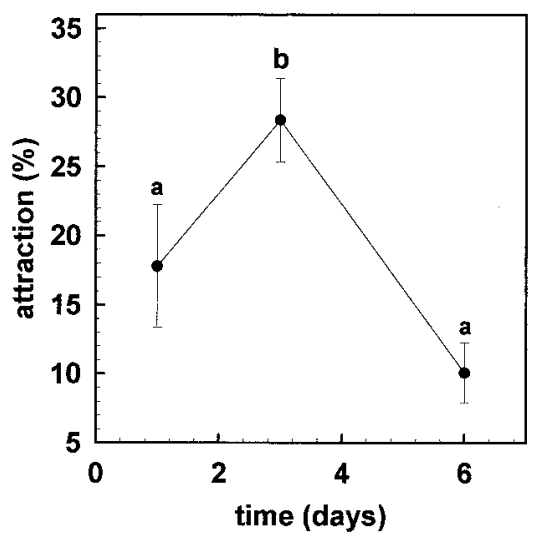

Fig. 3. Attraction of female S. calcitrans to feces sponges held in cages for 1-6 d. Different letters indicate significant differences due to the quantity of feces $(P<0.05)$. Each value is the mean of seven replicates $(n=30-35)$. Vertical bars indicate \pm SE.

sponges showed significant differences in attraction, with sponges held inside the colony cages for $3 \mathrm{~d}$ showing significantly greater attraction than sponges that were held for 1 or $6 \mathrm{~d}(F=7.5$; $\mathrm{df}=2,18 ; P=$ 0.004) (Fig. 3). Sponges held 1-3 d inside the colony cages appeared dry, but the sponges held $6 \mathrm{~d}$ felt quite wet and heavy with moisture. When 3-d sponges were aged in air before testing, no significant differences in attraction were seen regardless of length of aging, and 3 - $\mathrm{d}$ sponges held $28-31 \mathrm{~d}$ before assay were as attractive as 3 - $\mathrm{d}$ feces sponges that were not aged $(F=0.40$; $\mathrm{df}=2,15 ; P=0.68)$ (Fig. 4).

Female S. calcitrans were significantly more attracted to 0 - to 3 -d-old feces sponges $(25 \pm 2 \%)$ than were male flies $(14 \pm 4 \%, F=1.31 ; \mathrm{df}=2,18 ; P=0.03$, $n=10)$.

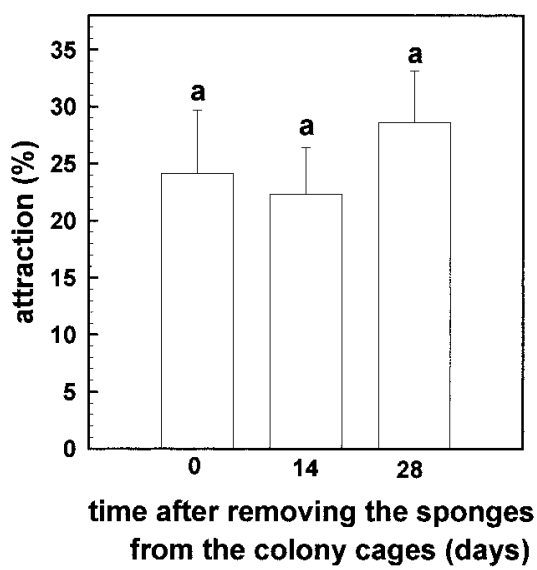

Fig. 4. Attraction of female S. calcitrans to conspecific aged feces on sponges aged by time after removal from rearing cage. Values marked with the same letter are not significantly different $(P=0.68)$. Each value is the mean of six replicates $(n=28-33)$. Vertical bars indicate \pm SE.

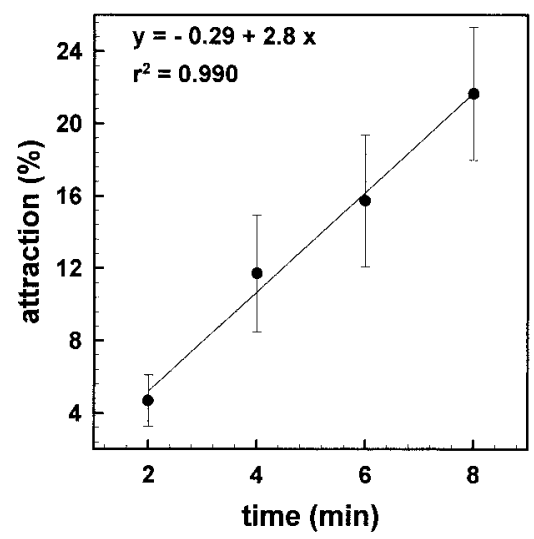

Fig. 5. Time-attraction relationship of female S. calcitrans to an extract of conspecific feces. Each value is the mean of nine replicates $(n=27-32)$. Vertical bars indicate $\pm \mathrm{SE}$.

The attraction of females to filter paper impregnated with feces extracted from sponges with a mixture of chloroform:methanol (2:1) increased as a function of exposure time $\left(\mathrm{y}=-0.29+2.8 \mathrm{x} ; R^{2}=0.990\right)$ (Fig. 5). Similarly, attraction increased linearly as a function of $\log _{10}$ feces extract concentration $(\mathrm{y}=$ $18.2+15.3 \mathrm{x} ; R^{2}=0.961$ ) (Fig. 6). Filter paper impregnated with this same feces extract and dried for $1 \mathrm{~h}$ showed a significantly greater attraction (15.8 \pm $4.1 \% \mathrm{SE})$ than when aged $15 \mathrm{~h}(3.0 \pm 2.0 \% \mathrm{SE}, F=11.2$; $\mathrm{df}=1,8 ; P=0.006 ; n=9)$.

Cage Extracts. Several of the solvent washes of rearing cages were attractive to female flies. Chloroform: methanol (2:1) was most active (16.8\%) and was not statistically different from water $(13.0 \%)$. Water was not different from either the methylene chloride $(11.5 \%)$ or hexane $(8.5 \%)$, all at $1 / 20$ of a cage equivalent (Waller-Duncan, $F=4.52 ; \mathrm{df}=2,14 ; P=0.05$, Fig. 7). Also, water-dampened sponge swabbings of cage inner surfaces were attractive at several dosages.

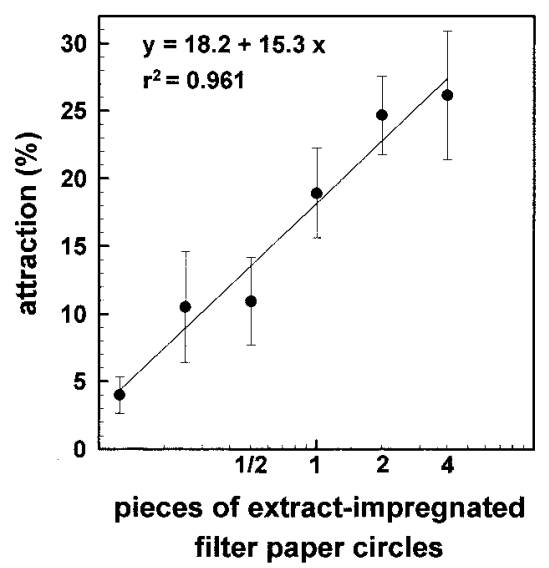

Fig. 6. Concentration-attraction relationship of female $S$. calcitrans to an extract of conspecific feces. Each value is the mean of seven replicates $(n=30-33)$. Vertical bars indicate $\pm \mathrm{SE}$. 


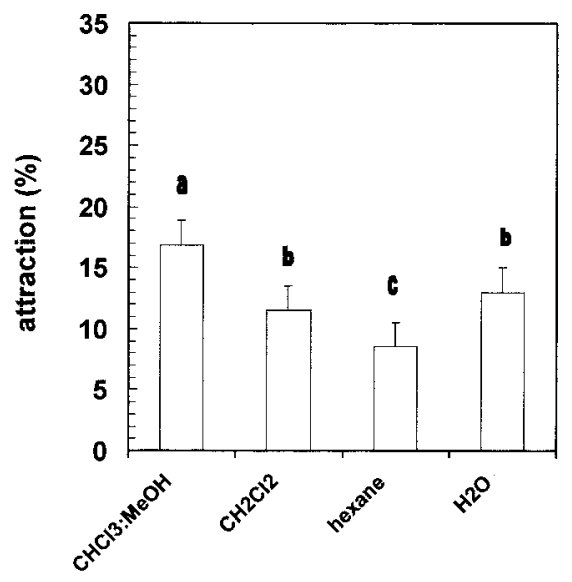

solvent used

Fig. 7. Attraction of female S. calcitrans to filter paper treated with $1 / 20$ of a cage wash made with solvents of different polarity. Different letters indicate significant differences $(P<0.05)$. Each value is the mean of four replicates $(n=27-33)$. Vertical bars indicate \pm SE.

Several tests were conducted with dose-response of hexane extracts by using $1 / 20,1 / 10$, and 1 cage equivalent as fresh extracts on filter paper. Similar attraction activity was seen as with methylene choride extracts, with good attraction when using an entire cage equivalent. Fractionation of hexane extracts on a silica gel gravity column after concentration to $20 \mathrm{ml}$ showed no activity in the hexane or hexane:ether $(5 \%)$ fraction, most activity in the hexane:ether $(15 \%)$ fraction, and some activity in the chloroform:methanol fraction. Recombination of all fractions was not better than the most active single fraction, and responses were not very high (data not shown).

An attractive chloroform:methanol extract was concentrated to $5 \mathrm{ml}$ and added to a silica gel column, and eluted as above, but no activity was observed in the residue from any fraction after rotary evaporation. It appeared that the bioactive materials were volatile and may have been lost during separation or concentration.

\section{Discussion}

Colony-reared stable flies were released directly from colony cages in mark-recapture experiments and were observed to return to the open rearing cages: these flies were reluctant to disperse (J.A.H., unpublished data). The validity of this observation was borne out in the current experiments with rearing cage extracts and sponges, in which several materials and treatments resulted in the capture of significantly large percentages of S. calcitrans females in the olfactometer system. Previous evaluation of this system showed no particular positional or other measurable bias (Alzogaray and Carlson 2000). These bias tests showed that human arm emanations typically attracted $20 \%$ of females and $10 \%$ of males in a 6 -min test, and that flies rarely were captured in the blank port. However, the current results show that fecal materials are even more attractive than human arm odors, because often $>50 \%$ of females responded, again with rare captures in the blank ports. The current results show that flies respond to a group of volatile chemicals in sponges and cage extracts that are likely to be different from odors in the human arm blend.

The good activity of cage extracts made with chloroform:methanol and water implies that the active odor(s) are somewhat polar, but this was contraindicated when methylene chloride and hexane cage extracts both showed activity in repeated trials when tested on sponges or filter paper. The activity was lost readily upon aging on porous materials such as filter paper, again indicating the presence of a volatile substance. Preliminary experiments with trapping of volatiles with Porapak-Q porous polymer traps were inconclusive (D.A.C., unpublished data). The polyunsaturated hydrocarbons and methylalkanes previously described as sex attractants may be present stable fly feces, although there was no evidence that they alone might be responsible for the responses observed herein. Such materials would have been separated by chromatography in the current experiments, and would have been present in the hydrocarbon fractions found to be unattractive. Currently we are not aware of reports of the attraction of stable flies to conspecific excreta. It was pointed out that the flies may be attracted to any odor, because it is better than doing nothing and starving (C.J. Geden, personal communication). Therefore, the hungry fly may be attracted to an odor that it would otherwise ignore, if there is no other stimulus. Presumably this was the argument for using Edamin (egg-based fly food) in the control port during early sex pheromone bioassays against male house flies, although female flies were not attracted to Edamin in any test materials or captured in test ports in these early olfactometer studies (Mayer and Thaggard 1966).

Because of the uncertainty regarding food odors, we conducted an olfactometer trial using freshly gathered goldenrod inflorescences (Solidago spp.) that were cut in early afternoon and tested within $30 \mathrm{~min}$; these showed little response by either sex (one to three flies). However, most flies immediately fed on flowers that were placed directly into the cage. Curiously, the flies appeared to move to the flowers only if given direct access to them. This is contrary to our expectation that goldenrod produced attractive volatiles signaling the presence of food, because flies are known to feed on these plants in nature (Tseng et al. 1983).

An explanation for aged sponges retaining their attractant activity is that living materials are present on the dampened feces sponges and that the responsible organisms remain viable for up to $30 \mathrm{~d}$, surviving and generating odors as they survive on fecal residues. Such fecal-derived organisms potentially could be useful in the attraction of stable flies to traps or toxic surfaces if suitably formulated. We intend to continue this effort to find chemical materials attractive to sta- 
ble flies, lacking a commercially advertised bait product that claims to attract stable flies.

\section{Acknowledgments}

We thank Donald Barnard for physical arrangements and interest in our work; and U. Bernier and R. Meagher for critically reading the manuscript. We thank Mandi Falkner for excellent technical assistance. Statistical analyses were performed by Victor Chew. This work was carried out while R.A.A. was in receipt of a fellowship from the Consejo Nacional de Investigaciones Científicas y Técnicas de Argentina.

\section{References Cited}

Alzogaray, R., and D. A. Carlson. 2000. Evaluation of Stomoxys calcitrans (Diptera: Muscidae) behavioral response to human and related odors in a triple cage olfactometer with insect traps. J. Med. Entomol. 37: 308-315.

Carlson, D. A., and J. W. Mackley. 1985. Polyunsaturated hydrocarbons in the stable fly. J. Chem. Ecol. 11: 14851496.

Carlson, D. A., M. S. Mayer, D. L. Silhacek, J. D. James, M. Beroza, and B. A. Bierl. 1971. Sex attractant pheromone of the house fly: isolation, identification and synthesis. Science 174: 76-78.

Cilek, J. K. 1999. Evaluation of various substances to increase adult Stomoxys calcitrans (Diptera: Muscidae) collections on Alsynite cylinder traps in north Florida. J. Med. Entomol. 36: 605-609.

Foil, L. D., and J. A. Hogsette. 1994. Biology and control of tabanids, stable flies and horn flies. Rev. Sci. Tech. Off. Int. Epiz. 13: 1125-1158.

Gouck, H. K., and C. E. Schreck. 1965. An olfactometer for use in the study of mosquito attractants. J. Econ. Entomol. 58: 589-590.

Hammack, L., and L. S. Hesler. 1996. Phenylpropanoids as attractants for adult $S$. calcitrans (Diptera: Muscidae). J. Med. Entomol. 33: 859-862.

Hogsette, J. A. 1992. New diets for production of house flies and stable flies (Diptera: Muscidae) in the laboratory. Vet. Entomol. 85: 2291-2294.

Holloway, M.T.P., and R. J. Phelps. 1991. The responses of Stomoxys spp. (Diptera: Muscidae) to traps and artificial odors in the field. Bull. Entomol. Res. 81: 51-55.

Jones, C. J., J. A. Hogsette, S. A. Isard, Y. J. Guo, G. Greene, and A. B. Broce. 1998. Using phenology to detect dispersal of stable flies in western Kansas, pp. 348-351. Proceedings, 13th Conf. on Biometeorology and Aerobiology, Albuquerque, NM. Nov 2-6.

Lorenzo Figueras, A. N., A. Kenigsten, and C. R. Lazzari. 1994. Aggregation in the haematophagous bug Triatoma infestans: chemical signals and temporal pattern. J. Insect Physiol. 40: 311-316.

Mayer, M. S., and J. D. James. 1971. Response of male Musca domestica to a specific olfactory attractant and its initial chemical purification. J. Insect Physiol. 17: 833-842.
Mayer, M. S., and C. W. Thaggard. 1966. Investigations of an olfactory attractant specific for males of the house fly, Musca domestica. J. Insect Physiol. 12: 891-897.

Mayer, M. S., D. L. Silhacek, D. A. Carlson, and J. D. James. 1972. Attraction of male house flies to cuticular hydrocarbons and feces of several other Dipteran species. Experientia 28: 1111-1112.

Metzger, R. 1995. Behavior. In: M. K. Rust, J. M. Owens and D. A. Reierson [eds.], Understanding and controlling the German cockroach. Oxford University Press, New York.

Mihok, S., E. K. Kang'ethe, and G. K. Kamau. 1995. Trials of traps and attractants for Stomoxys spp. (Diptera: Muscidae) J. Med. Entomol. 32: 283-289.

Mitchell, E. B., D. D. Hardee, and N. M. Wilson. 1975. Male boll weevils: studies relating to attractancy. J. Econ. Entomol. 68: 150-152.

Muhammed, S., J. F. Butler, and D. A. Carlson. 1975. Stable fly sex attractant and mating pheromones found in female body hydrocarbons. J. Chem. Ecol. 1: 387-398.

Mullens, B., A., N. Peterson, C. E. Dada, and R. K. Velten. 1995. Octenol fails to lure stable fly to insecticide. Calif. Agric. 49: 16-18.

Mumcuoglu, Y., R. Galun, and R. Ikan. 1986. The aggregation response of human body louse (Pediculus humanus) (Insecta: Anoplura) to its excretory products. Insect Sci. Applic. 7: 629-632.

Newson, H. D. 1977. Arthropod problems in recreation areas. Annu. Rev. Entomol. 22: 333-353.

Ondarza, R. N., A. Gutiérrez-Martínez, and E. A. Malo. 1986. Evidence for the presence of sex and aggregation pheromones from Triatoma mazzottii (Hemiptera: Reduviidae). J. Econ. Entomol. 79: 688-692.

Posey, K., D. R. Barnard, and C. E. Schreck. 1998. Triple cage olfactometer for evaluating mosquito (Diptera: $\mathrm{Cu}$ licidae) attraction responses. J. Med. Entomol. 35: $330-$ 334.

SAS Institute. 1989. SAS/STAT user's guide, version 6, 4th ed., vol. 2. SAS Institute, Cary, NC.

Schofield, C. J., and J. W. Patterson. 1977. Assembly pheromone of Triatoma infestans and Rhodnius prolixus nymphs (Hemiptera: Reduviidae). J. Med. Entomol. 13: 727-734.

Tseng, J. M., C. J. Jones, and J. A. Hogsette. 1983. Nectar feeding and the stable fly. J. Fla. Anti-Mosq. Assoc. 54: $40-41$.

Uebel, E. C., P. E. Sonnet, and R. W. Miller. 1975. Sex pheromone of the stable fly: isolation and preliminary identification of compounds that induce mating strike behavior. J. Chem. Ecol. 1: 377-385.

Wieman, G. A., J. B. Campbell, J. A. Deshazer, and I. L. Berry. 1992. Effects of stable flies (Diptera: Muscidae) and heat stress on weight gain and feed efficiency of feeder cattle. J. Econ. Entomol. 66: 1279-1280.

Wigglesworth, V. B. 1941. The sensory physiology of the human louse Pediculus humanus corporis de Geet (Anoplura). Parasitology 33: 67-109.

Received for publication 24 May, 2000; accepted 22 August 2000 